\title{
Usage of the device keeping the driver from falling asleep as a factor in reducing road accidents
}

\author{
Andrey Bogdanov ${ }^{1}$, Svetlana Popova ${ }^{1}$, Anton Kalugin ${ }^{1, ~ *}$, and Vitaliy Ivanov ${ }^{1}$ \\ ${ }^{1}$ FSBEI of Higher Education «South Ural State Agrarian Univerity», Chelyabinsk, Russia, 454080
}

\begin{abstract}
A significant proportion of internal transportation of goods is carried out by road. Statistics show that a large number of road traffic accidents, including fatalities, have to do with the driver falling asleep behind the wheel. A method was developed to stop the driver from falling asleep behind the wheel and a device to implement it; as a result, a patent for an invention was obtained. Some experimental studies were realized to implement this method and ensure the functioning of the device. As an example, the results of an experiment with KAMAZ 55102 motor vehicle were quoted, including the measure of the steering wheel angle $\left(\alpha_{\mathrm{BH}}=4,6^{\circ}\right)$ above which it is considered as steering of the wheel operator. In addition to that, the value of the minimum allowable number of steerings of the awake operator in a unit of time was given, and it came up to 0.5 steerings a second. Based on the experimental studies, some theoretical dependences describing the operation of the device preventing the driver from falling asleep at the wheel of a vehicle were developed.
\end{abstract}

\section{Relevance}

The basis of the modern economy is cargo transportation, which plays a leading role in the consumer market. Transportation of goods by road is the most acceptable and economically advantageous type of transportation [1,2].

As statistics show [3-6], a significant factor in road freight transportation is a large number of road accidents (road traffic accidents), including those related to the driver falling asleep behind the wheel. According to some reports [7] in about $30 \%$ of accidents on the roads with fatal consequences the drivers who fall asleep are to blame, so the problem of preventing falling asleep at the wheel is urgent.

The existing systems of stopping the drivers from dropping off are inconvenient to use, or quite costly [8-10]. We proposed a relatively inexpensive, but effective way to stop the driver from dropping off behind the wheel and a device for its implementation [11].

\footnotetext{
* Corresponding author: starfruitworks@gmail.com
} 


\section{Test object and equipment}

The operation of the device keeping the driver from falling asleep is based on the decreased human responses to the environment when falling asleep [12-15]. It manifests itself in the reduced number of steerings by the driver. The operation of the device keeping the driver from falling asleep can be described by a mathematical model $[12-14,16]$ :

$$
\left\{\begin{array}{l}
\text { if } n_{\text {подр }} \geq n_{\text {подр }}^{\text {до }}, \text { then } U_{\text {сигн }}=0, \\
\text { if } n_{\text {подр }}<n_{\text {подр }}^{\text {доп }}, \text { then } U_{\text {сигн }} \neq 0 .
\end{array}\right.
$$

where $n_{\text {подp }}$ - the number of steerings per unit of time, st./s; $n_{\text {nодр }}^{\text {доn }}-$ the minimum allowable number of steerings of the awake operator per unit of time, st./s; $U_{\text {сигн }}-$ the voltage supplied to the wake-up system, $\mathrm{V}$.

To wake up the driver, a sound signal or any other effect on a person can be used. In case of emergencies, when the driver does not respond to the awakening stimulus, it is possible to stop the moving vehicle automatically (fuel cutoff, etc.).

Some experimental studies were carried out with different types of vehicles to determine the value $n_{\text {nod }}^{\partial o n}$ in the system (1): a passenger car, a medium-duty vehicle and a truck [12-14]. As an example, let us review the experiments performed on KAMAZ 55102 truck [12].

The first situation corresponds to the state of falling asleep (drowsiness). At the same time, the body's reactions to the external environment are reduced and the driver stops driving the vehicle. To imitate this state during the experiment, the operator did not perform the steering, but simply held the steering wheel straight. The impact of external factors in this case caused minor rotations of the wheel in one direction or the other, determining the angle of wheel rotation under the influence of external factors $\alpha_{\mathrm{BH}}$. Taking into account that in this case the influence of the driver on the steering wheel is practically zero (as when the operator falls asleep), the angle $\alpha_{\mathrm{BH}}$ can serve as a threshold value by which it is possible to determine whether the operator has steered the wheel consciously or not. In other words, if the current angular displacement of the steering wheel $\alpha$ is below the value $\alpha_{\mathrm{BH}}\left(\alpha \leq \alpha_{\mathrm{BH}}\right)$, we will assume that the steering of the wheel was caused by external factors [12].

The second situation characterized the state of wakefulness, when the driver actively drove the vehicle, keeping the course stability. To do this, the operator of the wheeled vehicle carried out the necessary steering, as a rule, with a larger angular displacement than with steering movements caused by external factors. Therefore, we will assume that one steering made by a wakeful driver is one current angular displacement of the steering wheel $\alpha$, which exceeds the value $\alpha_{\text {вн }}\left(\alpha>\alpha_{\text {вн }}\right)$. Mathematically, this can be expressed as follows [12]:

$$
\left\{\begin{array}{l}
\text { if } \alpha \leq \alpha_{\theta H}, \text { then } n_{\text {nодp }}^{1}=0, \\
\text { if } \alpha>\alpha_{\theta H}, \text { then } n_{\text {nодp }}^{1}=1,
\end{array}\right.
$$

where $n_{\text {noдp }}^{1}$-is one steering, performed by the driver (operator) of the wheeled vehicle.

Before starting the experiments, a scale with divisions was plotted on the steering wheel (Fig. 1). When the vehicle moved along the selected straight section of the paved road, the movement of the scale divisions and the current time were recorded with a video camera. Then, according to the known mathematical charts, the current angular movements of the steering wheel $\alpha$ were determined.

An example of the results of one of the experiment series determining the angles of rotation of the steering wheel under the influence of external factors $\alpha_{\text {вн }}$ is given in Table 1. 
As can be seen from Table 1, the angles of rotation of the steering wheel under the influence of external factors in case of one angular displacement did not exceed $4.6^{\circ}$. Therefore, we can assume that $\alpha_{\mathrm{BH}}=4.6^{\circ}[12]$.

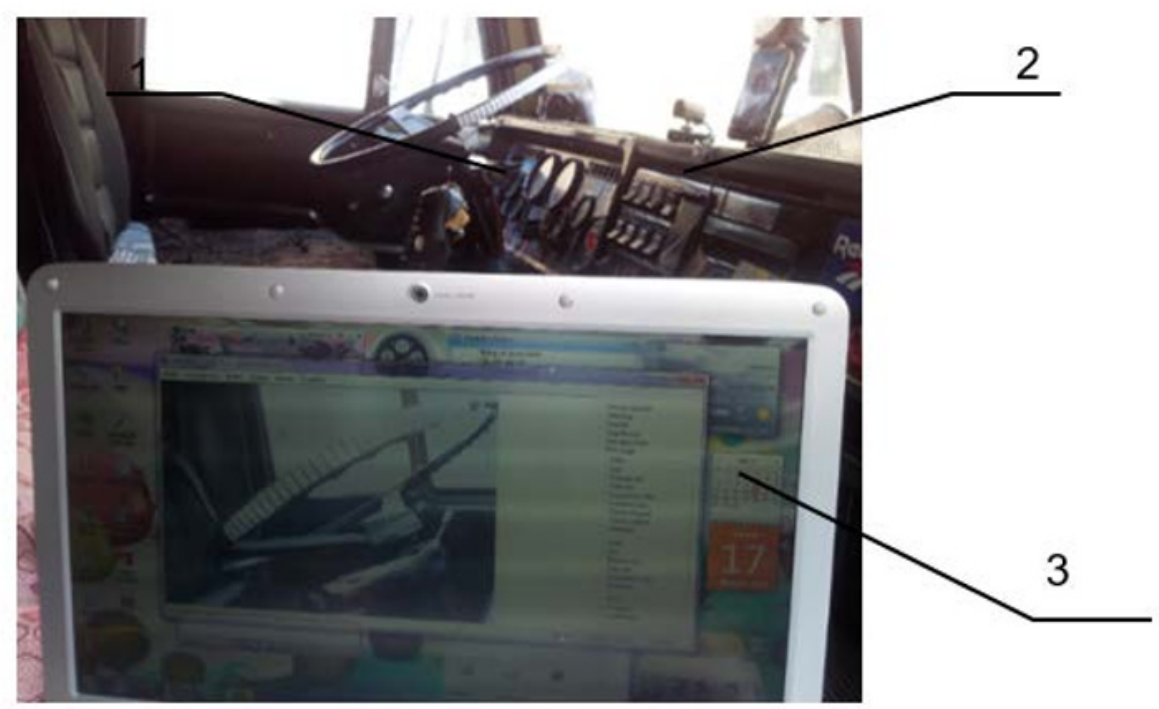

Fig. 1. The driver's cabin equipped for experimental research on defining the angles of the steering wheel rotation: 1 - a scale with divisions on the steering wheel; 2 - a videocamera; 3 -a recorder.

Table 1. A fragment of experiment results to determine the angles of steering wheel rotation under the influence of external factors (the experiment time $t=11 \mathrm{~s}$ )

\begin{tabular}{|c|c|c|c|c|c|c|c|c|}
\hline No. & $\begin{array}{l}\text { Number of } \\
\text { divisions in } \\
\text { one steering }\end{array}$ & $\begin{array}{c}\text { Angle of one } \\
\text { steering } \alpha_{\mathrm{BH}}, \\
\text { degr. }\end{array}$ & No. & $\begin{array}{l}\text { Number of } \\
\text { divisions in } \\
\text { one steering }\end{array}$ & $\begin{array}{l}\text { Angle of one } \\
\text { steering } \alpha_{\mathrm{BH}} \text {, } \\
\text { degr. }\end{array}$ & No. & $\begin{array}{l}\text { Number of } \\
\text { divisions in } \\
\text { one steering }\end{array}$ & $\begin{array}{l}\text { Angle of one } \\
\text { steering } \alpha_{\mathrm{BH}}, \\
\text { degr. }\end{array}$ \\
\hline 1. & 1 & 2.292 & 6. & 1 & 2.292 & 11. & 0.5 & 1.146 \\
\hline 2. & 0.5 & 1.146 & 7. & 0.5 & 1.146 & 12. & 2 & 4.584 \\
\hline 3. & 0.5 & 1.146 & 8. & 0.75 & 1.719 & 13. & 2 & 4.584 \\
\hline 4. & 1 & 2.292 & 9. & 0.75 & 1.719 & 14. & 2 & 4.584 \\
\hline 5. & 0.5 & 1.146 & 10. & 0.5 & 1.146 & 15. & 1.5 & 3.438 \\
\hline \\
\hline 10. & 1 & 2.292 & 45. & 0.5 & 1.146 & 50. & 0.5 & 1.146 \\
\hline 41. & 0.25 & 0.573 & 46. & 0.5 & 1.146 & 51. & 0.25 & 0.573 \\
\hline 42. & 0.5 & 1.146 & 47. & 0.5 & 1.146 & 52. & 0.25 & 0.573 \\
\hline 43. & 0.75 & 1.719 & 48. & 0.5 & 1.146 & & & \\
\hline 44. & 0.25 & 0.573 & 49. & 0.5 & 1.146 & & & \\
\hline
\end{tabular}

The results of one experiment series to determine the angles of the steering wheel rotation when performed directly by the driver are given in Table 2 . Table 2 shows that the rotation of the steering wheel can both be due to external factors and the operator when $\alpha>\alpha_{\mathrm{BH}}$. Since in this case $\alpha_{\mathrm{BH}}=4.6^{\circ}$, one angular displacement of the steering wheel will be considered as steering when $\alpha>4.6^{\circ}$. Taking this into account, expression (2) takes the form [12]:

$$
\left\{\begin{array}{l}
\text { if } \alpha \leq 4,6^{\circ}, \text { then } n_{\text {nодp }}^{1}=0 \\
\text { if } \alpha>4,6^{\circ}, \text { then } n_{\text {nодp }}^{1}=1 .
\end{array}\right.
$$


Table 2. A fragment of experiment results to determine the angles of steering wheel rotation under the influence of the operator (the experiment time $t=88 \mathrm{~s}$ )

\begin{tabular}{|c|c|c|c|c|c|c|c|c|}
\hline No. & $\begin{array}{c}\text { Number of } \\
\text { divisions in } \\
\text { one } \\
\text { steering }\end{array}$ & $\begin{array}{c}\text { Angle of } \\
\text { one } \\
\text { steering } \\
\alpha_{\mathrm{BH}} \text {, degr. }\end{array}$ & No. & $\begin{array}{l}\text { Number of } \\
\text { divisions in } \\
\text { one steering }\end{array}$ & $\begin{array}{c}\text { Angle of } \\
\text { one } \\
\text { steering } \\
\alpha_{\mathrm{BH}} \text {, degr. }\end{array}$ & No. & $\begin{array}{l}\text { Number of } \\
\text { divisions in } \\
\text { one steering }\end{array}$ & $\begin{array}{c}\text { Angle of } \\
\text { one } \\
\text { steering } \\
\alpha_{\mathrm{BH}} \text {, degr. }\end{array}$ \\
\hline 1. & 2 & 4.584 & 5. & 2 & 4.584 & 9. & 17 & 38.964 \\
\hline 2. & 0.5 & 1.146 & 6. & 1 & 2.292 & 10. & 15 & 34.380 \\
\hline 3. & 6 & 13.752 & 7. & 10 & 22.920 & 11. & 0.5 & 1.146 \\
\hline 4. & 8.5 & 19.482 & 8. & 2 & 4.584 & 12. & 8 & 18.336 \\
\hline \multicolumn{9}{|c|}{ 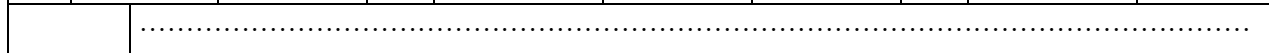 } \\
\hline 78. & 0.5 & 1.146 & 83. & 0.5 & 1.146 & 86. & 1 & 2.292 \\
\hline 79. & 1 & 2.292 & \begin{tabular}{|l|}
84. \\
\end{tabular} & 13 & 29.796 & 87. & 6.5 & 14.898 \\
\hline 80. & 2 & 4.584 & \begin{tabular}{|l|}
85. \\
\end{tabular} & 1 & 2.292 & 88. & 4.5 & 10.314 \\
\hline
\end{tabular}

After processing the experimental data, it was found that in the state of wakefulness, the driver performed about 5 steerings in 10 seconds, that is $n_{n o \partial p}^{\partial o n}=0.5$, st./s. Therefore, the value $n_{\text {nод } p}^{\partial o n}=0.5=0.5 \mathrm{st} . / \mathrm{s}$. can be taken as the minimum allowable number of steerings of the awake operator. In view of this, the system (1) takes the following form [12]:

$$
\left\{\begin{array}{l}
\text { if } n_{\text {подр }} \geq 0,5, \text { then } U_{\text {сигн }}=0, \\
\text { if } n_{\text {подр }}<0,5, \text { then } U_{\text {сигн }} \neq 0 .
\end{array}\right.
$$

The system (4) shows that the device keeping the driver from falling asleep has to give a signal to wake the driver when the number of steerings per unit of time is less than $0.5 \mathrm{st} . / \mathrm{s}$. (or lower, for example, 5 steerings in 10 seconds ) [12].

The main component (core) of the signal conversion unit of the device keeping the driver from falling asleep is the programmable 8-bit microcontroller AVR ATmega 8535. The microcontroller is functionally connected to the steering angle sensor, which is an incremental type encoder (Fig. 2). The output signal of this angular displacement transducer has the form shown in Fig. 3 [17].

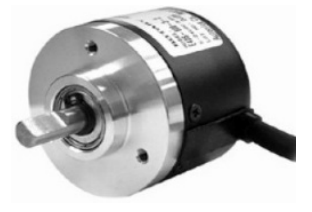

Fig. 2. Overall view of incremental type encoder

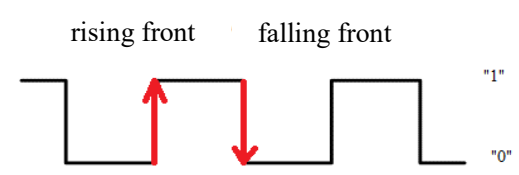

Fig. 3. Output signal of incremental type encoder

\section{Theoretical justification}

The main characteristic of the output signal is the number of generated pulses per one revolution of the sensor shaft or of the steering wheel (resolving power). In our case, one revolution of the sensor shaft corresponds to one revolution of the steering wheel shaft $\left(360^{\circ}\right)$. Then the resolving power of the output signal $\mathrm{R}_{\mathrm{S}}$ of the sensor can be determined with the help of the following expression: 


$$
R_{S}=\frac{360^{\circ}}{N_{\text {uмп.об. }}},
$$

where $N_{\text {имп.об }}$ - the number of pulses of the output signal per one revolution of the encoder shaft.

Given that an encoder that produces 600 pulses per revolution is used, then according to the expression (5) it is possible to determine the $\mathrm{R}_{\mathrm{S}}$ value, which equals to $0.6 \mathrm{deg} . / \mathrm{pulse}$.

Mathematically, the value of the current angular displacement of the steering wheel $\alpha$ can be expressed by the following expression:

$$
\alpha=R_{S} \cdot n_{\text {unn.cu }},
$$

where $n_{\text {unn.cu }}$ - the number of the output signal pulses of the incremental encoder of the current angular displacement of the steering wheel, which is recorded by the pulse counter.

Substituting expression (5) into (6), we obtain:

$$
\alpha=\frac{360^{\circ}}{N_{\text {uмn.об. }}} \cdot n_{\text {uлn.сч }},
$$

The process of reading the current angular displacement and determining $\alpha$ will be carried out until the time interval between the last and preceding recorded pulse exceeds the preset value. The process of reading the current angular displacement, depending on the time interval between the last and the previous recorded pulse, will be determined by the expression:

$$
\text { if } T_{\text {з.тек }}<T_{\text {з.усm }} \text {, then } n_{\text {uиn.cu }}=n_{\text {uиn.meк }} \text {, }
$$

where $T_{\text {з.тек }}$ - the current delay time between the last and the preceding recorded pulse, s; $T_{\text {з.усm }}$ - the set delay time between pulses, $\mathrm{s} ; n_{\text {или.тек }}-$ the current counted number of the output signal pulses of the incremental encoder.

If the delay time between the last and the preceding recorded pulse exceeds the set delay time, the calculation of the current displacement angle will be stopped and the pulse counter will be reset:

$$
\text { if } T_{\text {з.тек }} \geq T_{\text {з.усm }} \text {, then } n_{\text {uиn.си }}=0 \text {. }
$$

If the pulse counter is zeroed, the microcontroller will begin to read a new angular displacement (new steering).

Taking into account expressions (7), (8) and (9), we finally obtain the following set of conditions:

$$
\left[\begin{array}{l}
\text { if } T_{\text {з.тек }}<T_{\text {з.ycm }} \text {, then } \alpha=\frac{360^{\circ}}{N_{\text {uиn.oб. }}} \cdot n_{\text {имn.cu }}, \\
\text { if } T_{\text {з.тек }} \geq T_{3 . y c m}, \text { then } \alpha=0 .
\end{array}\right.
$$

\section{Conclusion}

The set of conditions (10) allows the signal converting unit to differentiate the steering wheel displacements from one another and determine the angle of one steering, which is the basis for the operation of the device keeping the driver from falling asleep. Further, a comparison of $\alpha$ with a given value of $\alpha_{\mathrm{BH}}$ (for KAMAZ $55102 \alpha_{\mathrm{BH}}=4.6^{\circ}$ ) is necessary according to the systems (2) and (3). When $\alpha \geq \alpha_{\mathrm{BH}}$ the signal conversion block of the device records the steering and adds it to the current value of the steerings. If the number of recorded steerings per unit of time 
does not exceed the minimum allowable value $n_{n o \partial p}^{\partial o n}\left(\right.$ for KAMAZ $55102 n_{n o \partial p}^{\partial o n}=0.5 \mathrm{st} . / \mathrm{s}$ ), the device will give out a waking signal according to the systems (1) and (4).

The introduction of the proposed device preventing the driver from falling asleep will reduce the number of road accidents, including fatalities.

\section{References}

1. Cargo transportation and economy [http://dispetchergruzoperevozok.info/gruzoperevozki-i-ekonomika].

2. The role and importance of motor transport [http://allrefs.net/c41/3r4zq/p22/].

3. Information on pedestrian collisions in the Russian Federation in 2010-2014 [https://www.gibdd.ru/stat/files/ped 2010-2014.pdf].

4. The RF economy losses from road accidents within 5 years amounted to 5.5 trillion rubles - D. Medvedev [http://www.interfax.by/news/belarus/1059160].

5. Facts and statistics. Access mode: http://www.sleepnet.ru/son-za-rulem/faktyi-i-statistika/

6. Road accidents in the Russian Federation within 9 months of 2016. Operational information-analytical review. - Moscow: FKU SIC BDD of the Ministry of Internal Affairs of Russia, 2016, 19 p.

7. Ovcharenko M.S. Increase of safety of transport agricultural machinery operators at the expense of development and introduction of engineering and technical and organizational measures: the author's abstract. dis. ... cand. tech. sciences. S.-Pb., 2007. 20 p.

8. Pat. 2214931 RF IPK7 V60K 28/06. Device for monitoring the state of the wakefulness of the driver of the vehicle, V. V. Pletnev; Applicant and patent attorney V. V. Pletnev. - No. 2001118939; claimed. 27.06.2003; publ. 27.10.2003.

9. Pat. 2390434 RF IPK7 V60K 28/02. A way of preventing the driver from falling asleep and the device for its implementation, V.V. Efanov; the applicant and the patent owner V. V. Efanov. - No. 2009123748; claimed. 22.06.2009; publ. 27.05.2010, Bul. №15.

10. Pat. 2478488 RF IPK7 V60K 28/06, B60T 7/14. The device controlling the functional condition of the driver, V.A. Nebolsin; applicant and patent holder V.A. Nebolsin. - No. 2011119137; claimed. 20.11.2012; publ. 10.04.2013, Bul. №10.

11. Pat. 2511186 RF IPK7 V60K 28/02, 28/06. A way of preventing the vehicle driver from falling asleep and the device for its implementation, A.V. Bogdanov, S.Yu. Popova; applicant and patent owner. Chelyabinsk State Agroengineering Academy. - No. 2012148343; claimed. 13.11.2012; publ. 10.04.2014, Bul. №10.

12. Bogdanov A.V., Popova S.Yu., Lakomov A.P., Popov Yu.A. Justification of the device to prevent the driver from falling asleep on KAMAZ-55102, AIC of Russia, No.73, P. 18-31 (2015)

13. Bogdanov A.V., Popova S.Yu., Polunin G.A. Justification of the device to prevent the driver from falling asleep behind the wheel of a wheeled vehicle, Protection and economics of labor, V.25, No. 4. pp. 12-19. (2016)

14. Bogdanov A.V., Popova S.Yu. Justification of the device to prevent the driver from falling asleep on the basis of the results of experimental studies with GAZ 33021, AIC of Russia, V.24, No. 1. pp. 29-37 (2017)

15. Bogdanov A.V., Popova S.Yu., Ivanov V.E. Laboratory installation for determining the indicators of the device to prevent the driver from falling asleep behind the wheel of the car, Life Safety, No.4 (196). pp. 30-33 (2017) 
16. Bogdanov A.V., Popova S.Yu. Improvement of the exchange rate stability as a factor in increasing the efficiency of wheeled mobile vehicles and reducing road accidents, Agrofood policy of Russia, No.1, P. 19-22 (2015)

17. Ivanov V.E. Realization of the process of reading the angular movements of the steering wheel in the system to prevent the operator of the mobile wheeled vehicle from falling asleep in the process of management, Proceedings of the IV All-Russian Student Conference (with international participation) / Ed. A.I. Sidorov, Chelyabinsk: Publishing Center of SUSU, P. 50-53 (2017) 